\title{
Article \\ Complex Structure Modification and Improvement of Properties of Aluminium Casting Alloys with Various Silicon Content
}

\author{
Anastasiya D. Shlyaptseva ${ }^{1}$, Igor A. Petrov ${ }^{1} \mathbb{D}$, Alexandr P. Ryakhovsky $^{1}$, Elena V. Medvedeva ${ }^{2}$ \\ and Victor V. Tcherdyntsev ${ }^{3, *}$ (D) \\ 1 Moscow Aviation Institute, Orshanskaya 3, 125993 Moscow, Russia; ShlyaptsevaAD@mai.ru (A.D.S.); \\ petrovia2@mai.ru (I.A.P.); ryahovskiyap@mai.ru (A.P.R.) \\ 2 Institute of Electrophysics, Ural Branch, Russian Academy of Science, Amudsena str., 106, \\ 620016 Yekaterinburg, Russia; lena@iep.uran.ru \\ 3 Institute of New Materials and Nanotechnology, National University of Science and Technology "MISIS", \\ Leninskii Prosp, 4, 119049 Moscow, Russia \\ * Correspondence: vvch@misis.ru; Tel.: +7-9104002369
}

check for updates

Citation: Shlyaptseva, A.D.; Petrov, I.A.; Ryakhovsky, A.P.; Medvedeva, E.V.; Tcherdyntsev, V.V. Complex Structure Modification and Improvement of Properties of Aluminium Casting Alloys with Various Silicon Content. Metals 2021, 11, 1946. https://doi.org/10.3390/ met11121946

Academic Editor: Wenming Jiang

Received: 15 October 2021

Accepted: 29 November 2021

Published: 1 December 2021

Publisher's Note: MDPI stays neutral with regard to jurisdictional claims in published maps and institutional affiliations.

Copyright: (c) 2021 by the authors. Licensee MDPI, Basel, Switzerland. This article is an open access article distributed under the terms and conditions of the Creative Commons Attribution (CC BY) license (https:// creativecommons.org/licenses/by/ $4.0 /)$.

\begin{abstract}
The possibility of using complex structure modification for aluminium casting alloys mechanical properties improvement was studied. The fluxes widely used in the industry are mainly intended for the modification of a single structural component of Al-Si alloys, which does not allow unifying of the modification process in a production environment. Thus, a new modifying flux that has a complex effect on the structure of Al-Si alloys has been developed. It consists of the following components: $\mathrm{TiO}_{2}$, containing a primary $\alpha$-Al grain size modifier; $\mathrm{BaF}_{2}$ containing a eutectic silicon modifier; KF used to transform titanium and barium into the melt. The effect of the complex titanium dioxide-based modifier on the macro-, microstructure and the mechanical properties of industrial aluminium-silicon casting alloys containing 5\%,6\%, 9\%, 11\% and 17\% Si by weight was studied. It was found that the tensile strength $\left(\sigma_{\mathrm{B}}\right)$ of $\mathrm{Al}-\mathrm{Si}$ alloys exceeds the similar characteristics for the alloys modified using the standard sodium-containing flux to $32 \%$, and the relative elongation ( $\delta$ ) increases to $54 \%$. The alloys' mechanical properties improvement was shown to be the result of the flux component's complex effect on the macro- and microstructure. The effect includes the simultaneous reduction in secondary dendritic arm spacing due to titanium, the refinement and decreasing size of silicon particles in the eutectic with barium and potassium, and the modifying of the primary silicon. The reliability of the studies was confirmed using up-to-date test systems, a significant amount of experimental data and the repeatability of the results for a large number of samples in the identical initial state.
\end{abstract}

Keywords: aluminium casting alloys; complex structure modification; titanium; barium; titanium dioxide; mechanical properties; microstructure; macrostructure

\section{Introduction}

Aluminium-silicon casting alloys are in demand due to the most favourable combination of casting, mechanical properties and a number of special operational properties [1]. Currently, there are several directions for the improvement of the alloys' properties, but melt modification does not become irrelevant, thus allowing achievement of the required level of the mechanical properties of alloys.

A large number of research works cover the issue of Al-Si alloy modifications [2-5], but there are no unified and reliable methods of Al-Si alloy modification with the various silicon rates so far. Most modifiers do not fully meet the production requirements. The fluxes widely used in the industry are mainly intended for the modification of a single structural component of Al-Si alloys, which does not allow unifying of the modification process in the production environment. 
Sodium-based modifiers are widely used [6] due to the availability of sodium salts and a good modifying ability of sodium as a modifier of the Al-Si eutectic. However, the scope of application of such modifiers is limited to alloys with the eutectic as the main structural component. Moreover, a significant disadvantage of alloy modification with sodium is the short modification effect and the increased tendency to form gas porosity [6].

In recent years, researchers have paid particular attention to the issues of the modification of Al-Si alloys using the complex impact on their structure [7-13]. The use of modifiers that give an impact on various structural components of the alloys is more effective than modification of a single phase. As a result, the scope of application of the modifier is expanded. However, such complex compositions often contain expensive substances, and this disadvantage limits the scope of their application.

Therefore to reduce the cost of such compositions, it is necessary to find new, available complex modifiers, develop production technologies and use such modifiers for the aluminium melt.

This paper describes the changes in the mechanical properties, macro- and microstructure of various alloys as a result of melt treatment with a complex modifying flux consisting of $19-29$ wt. $\% \mathrm{TiO}_{2}+32-40 \mathrm{wt} . \% \mathrm{BaF}_{2}+34-42 \mathrm{wt} . \% \mathrm{KF}$ mixture [14].

To ensure eutectic modification $(\alpha-\mathrm{Al}+\mathrm{Si})$, the flux contains barium, a surface-active element for eutectic silicon, which is injected using fluoride. When barium is injected into the melt, the particles of eutectic silicon are refined and rounded. The main advantage of barium use is the long-term preservation of the modifying ability [15-19]. Barium fluoride is an available substance with a relatively low cost.

To modify the primary $\alpha$-Al grain size, we propose to use titanium, the most efficient grain modifier in aluminium alloys, which refines the $\alpha$-Al dendrites in Al-Si alloys [20-24]. Titanium is introduced using its oxide compounds instead of traditional ligatures and salts. Titanium dioxide is the most available and inexpensive compound among titaniumcontaining substances.

To modify Al-Si alloys, titanium dioxide should be reduced to titanium by melting with the subsequent formation of additional $\mathrm{TiAl}_{3}$ crystallization centres. Therefore, the flux consists of potassium fluoride, which improves the wettability of titanium dioxide with aluminium and dissolves the oxide, thereby ensuring the aluminothermic reduction of the oxide to metal [25-28]. Potassium fluoride has a relatively low cost and increases the probability of barium transition from fluoride to the melt due to the formation of the low-melting eutectic [29].

The paper describes the study of the complex flux versatility, i.e., the use of this modifier for aluminium casting alloys with the various silicon content.

\section{Materials and Methods}

The following widely-used alloys were selected for the study:

Hypoeutectic alloy with copper of Al-Si-Cu system (Alloy 1); hypoeutectic alloys with magnesium of Al-Si-Mg system (Alloy 2) and (Alloy 3); eutectic binary alloy of Al-Si system (Alloy 4); hypereutectic piston alloy of $\mathrm{Al}-\mathrm{Si}-\mathrm{Cu}-\mathrm{Mg}-\mathrm{Ni}$ system (Alloy 5 ). The chemical composition of the alloys is listed in Table 1.

Table 1. Elemental composition of the study alloys according to spectral analysis data (average values).

\begin{tabular}{|c|c|c|c|c|c|c|c|c|c|c|}
\hline \multicolumn{2}{|l|}{ Alloy } & \multicolumn{9}{|c|}{ Elements (wt. \%) } \\
\hline System & $\mathbf{N}^{\mathbf{o}}$ & Si & $\mathrm{Fe}$ & $\mathrm{Cu}$ & Mg & Mn & $\mathbf{N i}$ & Zn & Ti & Al \\
\hline Al-5wt.\% Si-Cu & Alloy 1 & 5.45 & 0.64 & 1.21 & 0.35 & 0.19 & 0.02 & 0.22 & 0.05 & base \\
\hline Al-6 wt. $\%$ Si-Mg & Alloy 2 & 5.94 & 0.37 & - & 0.19 & 0.006 & - & 0.01 & 0.011 & base \\
\hline Al-9 wt.\% Si-Mg & Alloy 3 & 9.28 & 0.37 & 0.09 & 0.31 & 0.25 & 0.04 & 0.02 & 0.026 & base \\
\hline 12 wt. $\%$ Si & Alloy 4 & 11.53 & 0.36 & 0.002 & 0.0006 & 0.0026 & - & 0.01 & 0.009 & base \\
\hline Al-17 wt.\% Si-Cu-Mg-Ni & Alloy 5 & 17.02 & 0.36 & 1.03 & 0.88 & 0.009 & 1.35 & 0.012 & 0.007 & base \\
\hline
\end{tabular}


Experimental alloy meltings were carried out in a muffle electric resistance furnace. The weight of a single melt was $900 \mathrm{~g}$. The melt was pre-degassed by blowing with an inert gas (argon).

The melt surface was covered with an even layer of the flux under study at a temperature of $770-790{ }^{\circ} \mathrm{C}$. After holding for 8-10 min at a given temperature, the flux was thoroughly mixed deep into the melt for 3-5 min. Then, the melt was held for 15-20 min, and the slag was removed from the melt surface. The temperature of the melt was brought to $710{ }^{\circ} \mathrm{C}$, then, the melt was poured into the prepared sandy-clay mould.

The melt was treated with the standard sodium-containing flux $(25 \% \mathrm{NaF}+62.5 \%$ $\mathrm{NaCl}+12.5 \% \mathrm{KCl}$ [30]) at a temperature of $730-750{ }^{\circ} \mathrm{C}$. The melt surface was covered with an even layer of the flux in the amount of $1.5 \%$ by the melt weight. After holding for $10 \mathrm{~min}$ at a given temperature, the flux was thoroughly mixed deep into the melt. Then, the slag was removed from the melt surface, and the melt was held.

Alloys 1 and 2, after modification, were subjected to heat treatment in accordance with ASTM B917/B917M-12 in the T6 mode, alloy 3 was subjected to heat treatment in the T62 mode.

The mechanical properties of the alloys (ultimate strength (tensile strength) $\sigma_{\mathrm{B}}(\mathrm{MPa})$, relative elongation $\delta(\%)$ ) were determined in accordance with ASTM B557M-15 using Instron 5982 testing machine.

In each experiment, 4 samples were tested. Each experiment was repeated three times.

Microstructural studies were conducted using Imager.Z2m AXIO universal research microscope (Carl Zeiss, Microscopy GmbH, Göttingen, Germany).

For etching the macrostructure of alloys $2-5$, the Hume-Rothery reagent $\left(15 \mathrm{~g}\right.$ of $\mathrm{CuCl}_{2}$, $100 \mathrm{~mL}$ of $\left.\mathrm{H}_{2} \mathrm{O}\right)$ was used, for alloy 1 , the Keller's reagent $\left(2.5 \% \mathrm{HNO}_{3}, 1.5 \% \mathrm{HCl}, 0.5 \%\right.$ $\mathrm{HF}$ ) was used [31].

Quantitative analysis of the microstructure (the average area of eutectic silicon, the average size of primary silicon and $\alpha$-Al dendrites) was carried out using specialized ImageExpert Pro 3.7 software, version 3.7.5.0, NEXSYS, Moscow, Russia using three images for each sample. The photos were processed according to the following operations: photo resizing, scale selection, binarization, determination of the object of study by colour, etc. For images processing, ImageExpert Pro 3.7 software uses built-in algorithms (techniques corresponding to the international standard ASTM E112-10).

To measure the size of an $\alpha$-Al dendrite, secondary dendrite arm spacing (SDAS) was determined. SDAS was evaluated as reported in [32] by measuring thirty dendrites for each sample, employing three images at $50 \times$ magnification.

The primary Si particle size was evaluated as the maximum Feret's diameter.

The chemical (elemental) composition of the prototypes was studied using CCD-based Q4 TASMAN-170 spark optical emission spectrometer. The control of Q4 TASMAN-170 spectrometer is carried out from a desktop computer using special QMatrix software, version 3.8.1, Bruker Quantron GmbH, Kalkar, Germany.

Before the start of the chemical (elemental) composition analysis, Q4 TASMAN-170 spectrometer was set up using special calibration samples. The samples for the chemical (elemental) composition analysis were made from the sink head of the casting and had the size of $25 \times 25 \times 10 \mathrm{~mm}$.

\section{Results and Discussion}

The results of mechanical tests of various silumins treated with the developed flux and the standard sodium-containing flux are given in Table 2. The experiments showed that the treatment with the developed complex flux improves the mechanical properties (tensile strength $\sigma_{\mathrm{B}}$ and relative elongation $\delta$ ) of eutectic, hypoeutectic and hypereutectic Al-Si alloys, compared to the similar parameters of the alloys treated with the conventional industrial flux. 
Table 2. Mechanical properties of Al-Si alloys, the average area of eutectic Si and the average size of primary $\mathrm{Si}$, SDAS, depending on the type of treatment (sand casting).

\begin{tabular}{|c|c|c|c|c|}
\hline Alloy & Properties & Unmodified & Standard Flux & Complex Flux \\
\hline \multirow{4}{*}{ Alloy 1 (T6) } & $\sigma_{\mathrm{B}}, \mathrm{MPa}$ & $316 \pm 6$ & $317 \pm 5$ & $367 \pm 7$ \\
\hline & $\delta, \%$ & $0.67 \pm 0.1$ & $1.25 \pm 0.2$ & $1.92 \pm 0.15$ \\
\hline & $\mathrm{S}_{\mathrm{Si} \text { eut }}, \mu \mathrm{m}^{2}$ & $8.84 \pm 0.25$ & $6.75 \pm 0.41$ & $5.42 \pm 0.5$ \\
\hline & $\mathrm{SDAS}, \mu \mathrm{m}$ & $35.71 \pm 4.15$ & $35.59 \pm 5.18$ & $25.47 \pm 2.14$ \\
\hline \multirow{4}{*}{ Alloy 2 (T6) } & $\sigma_{\mathrm{B}}, \mathrm{MPa}$ & $239 \pm 10$ & $235 \pm 6$ & $262 \pm 4$ \\
\hline & $\delta, \%$ & $0.98 \pm 0.25$ & $3.72 \pm 0.3$ & $4.89 \pm 0.3$ \\
\hline & $\mathrm{S}_{\mathrm{Si} \text { eut }}, \mu \mathrm{m}^{2}$ & $19.48 \pm 2.2$ & $2.21 \pm 0.17$ & $1.99 \pm 0.2$ \\
\hline & SDAS, $\mu \mathrm{m}$ & $37.69 \pm 2.15$ & $35.23 \pm 2.18$ & $30.33 \pm 2.08$ \\
\hline \multirow{4}{*}{ Alloy 3 (T62) } & $\sigma_{\mathrm{B}}, \mathrm{MPa}$ & $255 \pm 10$ & $245 \pm 10$ & $323 \pm 6$ \\
\hline & $\delta, \%$ & $1.05 \pm 0.2$ & $2.9 \pm 0.15$ & $3.60 \pm 0.15$ \\
\hline & $\mathrm{S}_{\text {Si eut }}, \mu \mathrm{m}^{2}$ & $12.55 \pm 1.61$ & $3.91 \pm 0.28$ & $2.68 \pm 0.37$ \\
\hline & SDAS, $\mu \mathrm{m}$ & $28.35 \pm 3.1$ & $30.98 \pm 2.9$ & $21.72 \pm 2.07$ \\
\hline \multirow{4}{*}{ Alloy 4} & $\sigma_{\mathrm{B}}, \mathrm{MPa}$ & $140 \pm 6$ & $160 \pm 9$ & $175 \pm 9$ \\
\hline & $\delta, \%$ & $2.27 \pm 0.2$ & $8.05 \pm 0.7$ & $12.2 \pm 0.8$ \\
\hline & $\mathrm{S}_{\mathrm{Si} \mathrm{eut}}, \mu \mathrm{m}^{2}$ & $53.71 \pm 6.0$ & $0.56 \pm 0.05$ & $0.48 \pm 0.09$ \\
\hline & $\mathrm{SDAS}, \mu \mathrm{m}$ & $37.98 \pm 5.03$ & $36.01 \pm 4.5$ & $27.6 \pm 2.2$ \\
\hline \multirow{4}{*}{ Alloy 5} & $\sigma_{\mathrm{B}}, \mathrm{MPa}$ & $150 \pm 4$ & - & $182 \pm 4$ \\
\hline & $\delta, \%$ & $0.38 \pm 0.05$ & - & $0.74 \pm 0.15$ \\
\hline & $\mathrm{S}_{\mathrm{Si} \text { eut }}, \mu \mathrm{m}^{2}$ & $30.34 \pm 4.01$ & - & $21.70 \pm 3.89$ \\
\hline & $\mathrm{Si}^{\mathrm{I}}, \mu \mathrm{m}$ & $92 \pm 12$ & - & $46 \pm 9$ \\
\hline
\end{tabular}

The significant improvement in the alloys' mechanical properties upon modification with an experimental flux is caused by the complex impact on the alloy structure.

Measurements of SDAS and the average area of eutectic Si were carried out for all samples to observe the difference between the modified and unmodified specimens. As Table 2 demonstrates, the average area of eutectic $\mathrm{Si}$ and the SDAS decreased in all alloys after the addition of complex flux.

The microstructure of the eutectic unmodified alloy Al-12 wt\% Si (alloy 4) features a coarse eutectic $(\alpha-\mathrm{Al}+\mathrm{Si})$ in the form of large needles and plates $\left(\mathrm{S}_{\mathrm{Si}}\right.$ eut $\left.=53.71 \mu \mathrm{m}^{2}\right)$ with large $\alpha$-Al dendrites (SDAS $=37.98 \mu \mathrm{m}$ ) (Figure 1a).

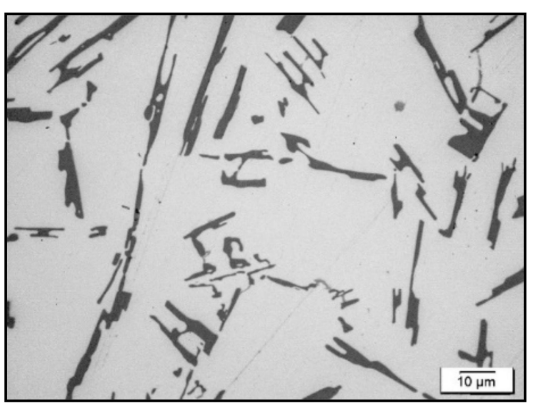

(a)

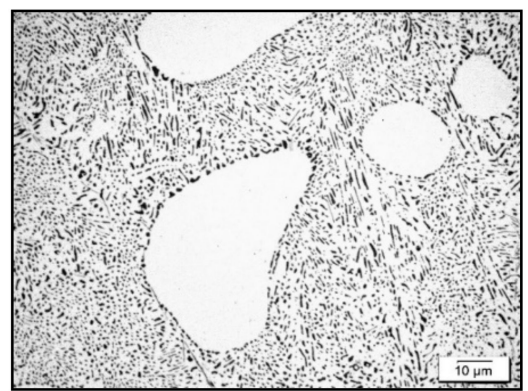

(b)

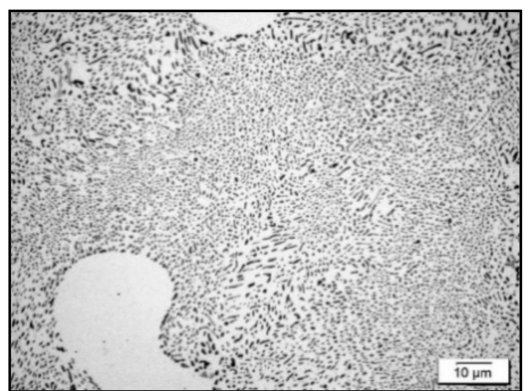

(c)

Figure 1. Microstructure of eutectic alloy 4 depending on treatment: (a) untreated; (b) standard flux; (c) complex flux. 
Treatment of alloy 4 with such fluxes results in the refinement of eutectic silicon, and the particles of eutectic silicon become globular (Figure $1 b, c)$. The average area of eutectic silicon particles in a modified alloy is two orders of magnitude smaller than the area of eutectic silicon in an unmodified alloy (Table 2). However, treatment with a complex flux (Figure 1c) leads to a greater fragmentation of the eutectic compared to treatment with a standard flux (Figure 1b). The average particle area of eutectic silicon decreases from $0.56 \mu \mathrm{m}^{2}$ for standard flux to $0.48 \mu \mathrm{m}^{2}$ for complex flux. The developed flux also affects the $\alpha$-Al dendrites, SDAS in alloy 4 was reduced by $27 \%$ (Table 2). Titanium, as a component of the flux, facilitates refinement of the alloy macrograin, as clearly seen in the photographs of the macrostructure (Figure 2c). The standard flux does not change the macrograin size (Figure $2 \mathrm{~b}$ ) compared to the unmodified alloy (Figure 2a). Due to grain refinement, the mechanical properties of the alloy are also improved. Compared to the unmodified alloy, the relative elongation increases 5.4 times $(12.2 \%)$ and the tensile strength increases by $25 \%$ $(175 \mathrm{MPa})$. The resulting values are lower in the case of treatment with a standard flux, $\delta$, by $52 \% ; \sigma_{\mathrm{B}}$ by $9.4 \%$.

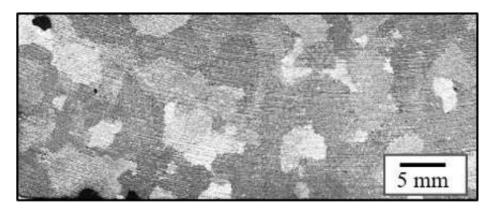

(a)

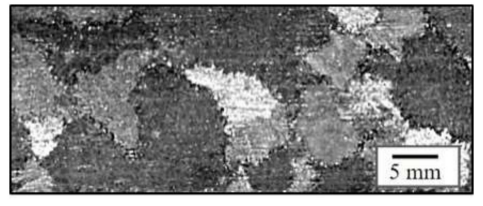

(b)

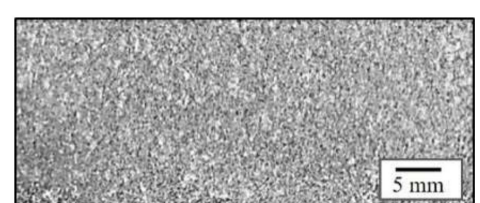

(c)

Figure 2. Macrostructure of eutectic alloy 4 depending on treatment: (a) untreated; (b) standard flux; (c) complex flux.

The main structural components of hypoeutectic $\mathrm{Al}-\mathrm{Si}$ casting alloys are $\alpha$-Al dendrites and aluminium-silicon eutectic (Figure $3 a, b$ ).

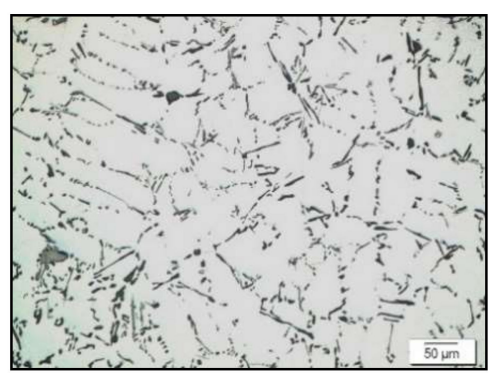

(a)

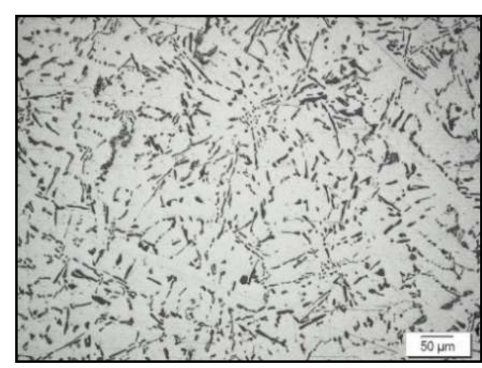

(d)

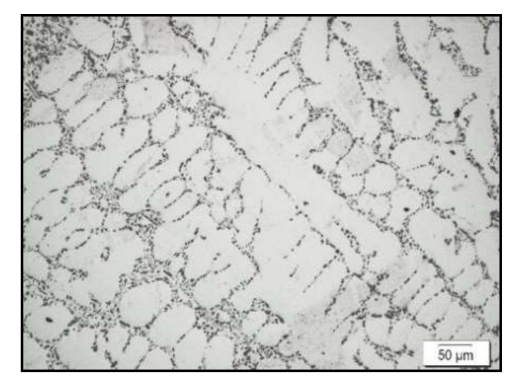

(b)

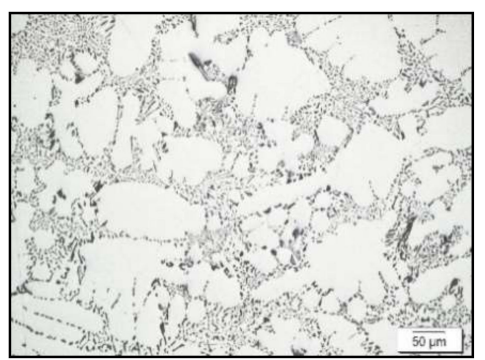

(e)

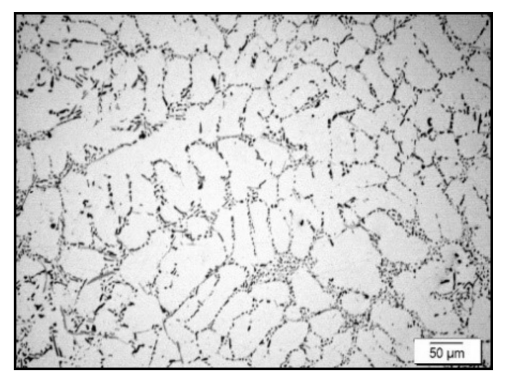

(c)

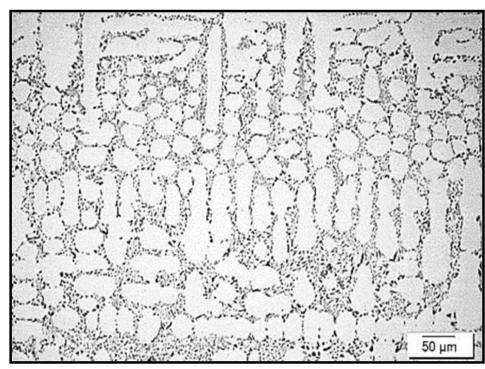

(f)

Figure 3. Microstructure of hypoeutectic alloys: (a) Alloy 2, untreated; (b) Alloy 2, standard flux; (c) Alloy 2, complex flux; (d) Alloy 3, untreated; (e) Alloy 3, standard flux; (f) Alloy 3, complex flux.

Modification with the complex flux significantly affects all structural components of hypoeutectic silumins (Figure 3c,f). Compared to the alloy treated with the standard flux 
(Figures $3 \mathrm{~b}$,e and $4 \mathrm{~b}, \mathrm{e}$ ), the complex flux reduces SDAS, which is most expressed in Al-9 wt.\% Si-Mg alloy (Alloy 3) (Figure 3e), as well as refines alloy macrograins (Figure 4c,f). In detail, SDAS in alloy 2 was reduced by $19 \%$ and in alloy 3 by $23 \%$. This effect on the structure is exerted by titanium transformed from the dioxide into the melt and contained in the modified alloys Al-7 wt.\% Si-Mg (Alloy 2) and Al-9 wt.\% Si-Mg (Alloy 3) in the amount of $0.119 \mathrm{wt} . \%$ and $0.126 \mathrm{wt} . \%$, respectively. Moreover, the complex flux refines eutectic silicon more intensely than sodium-containing flux. The size of the eutectic area was strongly reduced after complex flux addition: in alloy 2 it was reduced by $89 \%$ and in alloy 3 by $78 \%$ compared to the unmodified alloy. The effect on the eutectic in the complex flux is exerted by two surface-active elements-barium and potassium.

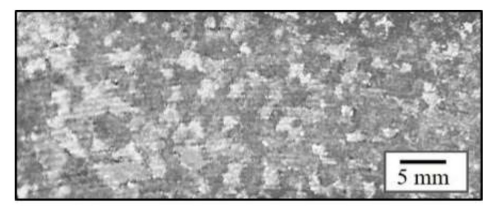

(a)

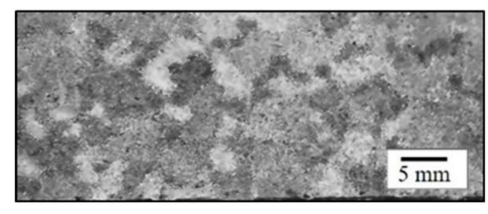

(d)

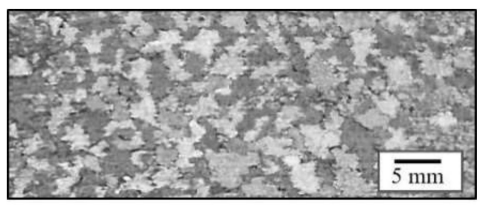

(b)

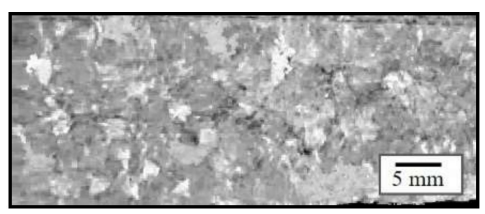

(e)

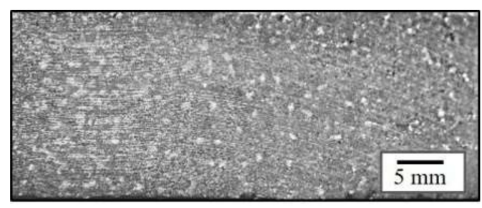

(c)

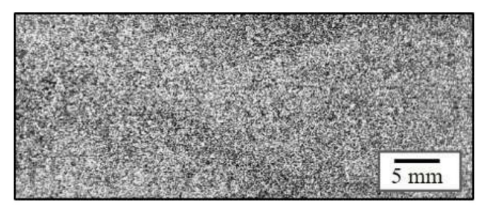

(f)

Figure 4. Macrostructure of hypoeutectic alloys: (a) Alloy 2, untreated; (b) Alloy 2, standard flux; (c) Alloy 2, complex flux; (d) Alloy 3, untreated; (e) Alloy 3, standard flux; (f) Alloy 3, complex flux.

The mechanical properties of hypoeutectic alloys were determined after heat treatment in the T6 mode (Alloy 2) and the T62 mode (Alloy 3) (Table 2). The greatest improvement in properties is achieved when using the complex flux. Compared to unmodified alloy 2 and 3 , $\delta$ increases 5 times and 3.4 times, respectively, $\sigma_{B}$ increases by $7 \%$ and $27 \%$, respectively. $\delta$ of alloys 2 and 3 treated with a complex flux is higher than upon treatment with a standard flux by $31 \%$ and $24 \%$, respectively; $\sigma_{\mathrm{B}}$ is higher by $11 \%$ and $32 \%$, respectively.

Al-5 wt.\% Si-Cu alloy (Alloy 1) has a wider crystallization range compared to the previously considered silumins and has a relatively high strength-more than $300 \mathrm{MPa}$ (Table 2). However, the study alloy has low values of the relative elongation- $-0.67 \%$.

The treatment of alloy 1 with a complex modifying flux based on titanium dioxide makes it possible to increase the relative elongation of the alloy by 2.9 times, and the strength by $16 \%$. The resulting values of the mechanical properties of the experimental alloy are also higher than upon treatment with the standard flux: the relative elongation increases by $54 \%$, and the strength increases by $16 \%$.

The significant improvement of the alloy properties upon modification with an experimental flux is a consequence of the complex impact upon the structure of the copper Al-Si alloy. The main structural components in the alloy are aluminium dendrites and aluminium-silicon eutectic (Figure 5a). Figure 5 shows the structure of the alloy heat treated according to the T6 mode. The result of heat treatment is not only the complete dissolution of copper and magnesium in aluminium but also the partial refinement and spheroidization of eutectic silicon [32].

Complete refinement and spheroidization of eutectic silicon is achieved as a result of modification. The average area of eutectic Si shrank by 39\% after complex flux addition and by $23 \%$ after standard flux addition. When treated with the standard flux, the eutectic is modified with sodium (Figure 5b), when modified with the experimental flux-with barium, successfully transferred into the melt in the amount of $0.019 \mathrm{wt} . \%$ (Figure 5c), and potassium transferred into the melt in amount of $0.002 \mathrm{wt} . \%$. However, in contrast 
to the standard flux, the developed modifier also refines aluminium dendrites (Figure $5 \mathrm{c}$ ) with the volume fraction exceeding $70 \%$ [33]. SDAS in alloy 1 was reduced by $29 \%$. The macrograin is refined (Figure 6c). Such an effect on the structure is exerted by titanium transformed from the dioxide into the alloy and contained in the amount of $0.186 \%$ of the alloy weight.

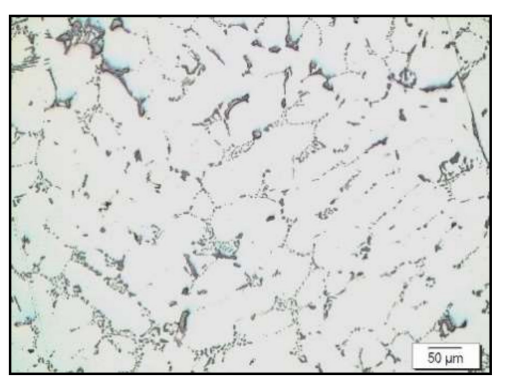

(a)

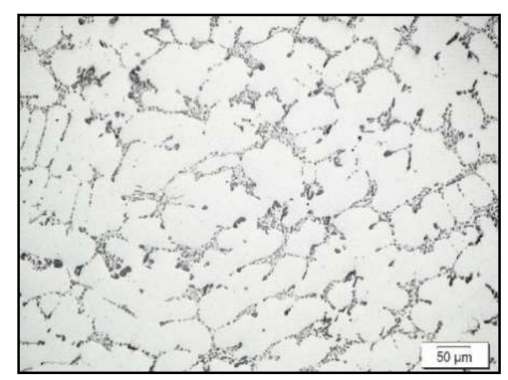

(b)

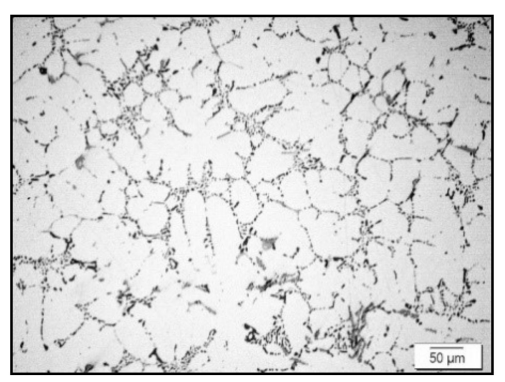

(c)

Figure 5. Microstructure of hypoeutectic alloy with copper, Alloy 1: (a) untreated; (b) standard flux; (c) complex flux.

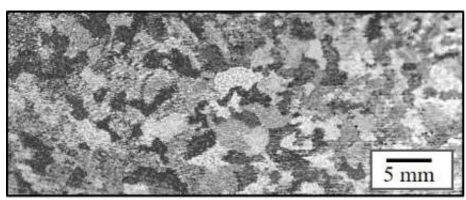

(a)

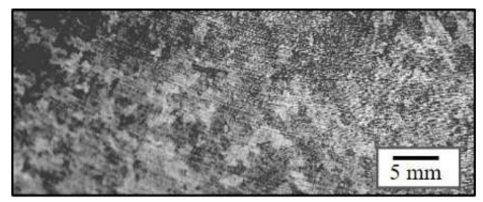

(b)

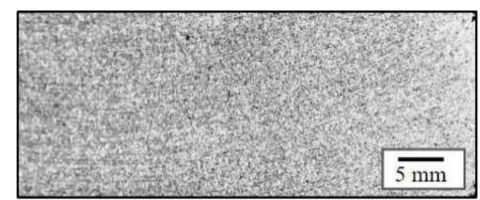

(c)

Figure 6. Macrostructure of hypoeutectic alloy with copper, Alloy 1: (a) untreated; (b) standard flux; (c) complex flux.

Al-17wt.\% Si-Cu-Mg-Ni alloy (Alloy 5) is assigned to piston alloys and has high hardness, even at elevated temperatures. However, it has low plasticity due to the high volume fraction of excess phases. Modification can improve the mechanical properties of the alloy. The studies of the influence of the developed modifier on the mechanical properties of the hypereutectic alloy showed that the alloy treatment with a complex flux increases the alloy strength by 1.2 times $(182 \mathrm{MPa})$, and the relative elongation by about 2 times $(0.74 \%)$.

Figure 7a shows the structure of the hypereutectic alloy. The casting alloy structure has primary crystals of the silicon phase in the shape of polyhedrons. Aluminium-silicon eutectic has a coarse structure. Modification with a complex flux based on titanium dioxide reduces the size of primary silicon by 2 times to $46 \mu \mathrm{m}$, contributes to the refinement of the eutectic (Figure $7 \mathrm{~b}$ ), and refines macrograins (Figure 8b), while the standard flux does not affect the properties and structure of alloy 5 .

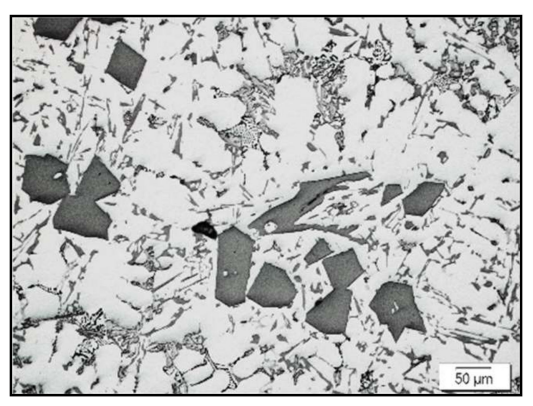

(a)

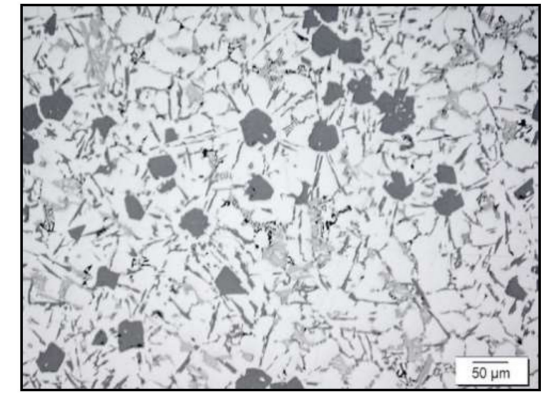

(b)

Figure 7. Microstructure of hypereutectic alloy 5: (a) untreated; (b) complex flux. 


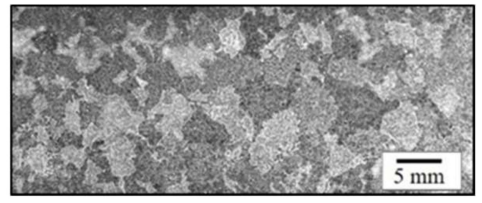

(a)

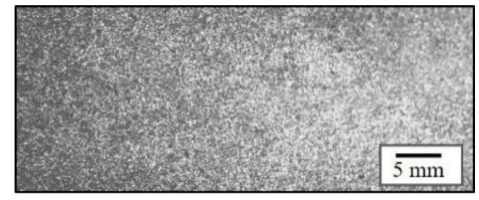

(b)

Figure 8. Macrostructure of hypereutectic alloy 5: (a) untreated; (b) complex flux.

It should be noted that the eutectic phase's size is different among the unmodified alloys: 8-19 $\mu \mathrm{m}^{2}$ for alloys with less silicon (alloys 1, 2 and 3) to $53 \mu \mathrm{m}^{2}$ for eutectic alloy 4 , but such a difference is reduced after modification with flux. Unmodified alloy 4 , having a lower content of alloying elements, has larger eutectic particle sizes. This behaviour is due to the large presence of alloying elements in alloys 1,2 and 3 favouring nucleation of intermetallics into the eutectic area, thus limiting the growth of silicon [34].

The positive effect of the modifier on various structural components of Al-Si alloys is stipulated by the modifying impact of titanium and barium. Spectral analysis data (Figure 9) confirm that Ti and Ba are successfully transformed into the melt in the amount sufficient for modification and within permissible concentration (Figure 9). The concentration of modifying elements in alloys is provided in optimal amounts: $\mathrm{Ti}-0.1-0.2 \mathrm{wt} \%$ and $\mathrm{Ba}-0.010-0.020 \mathrm{wt} \%$.

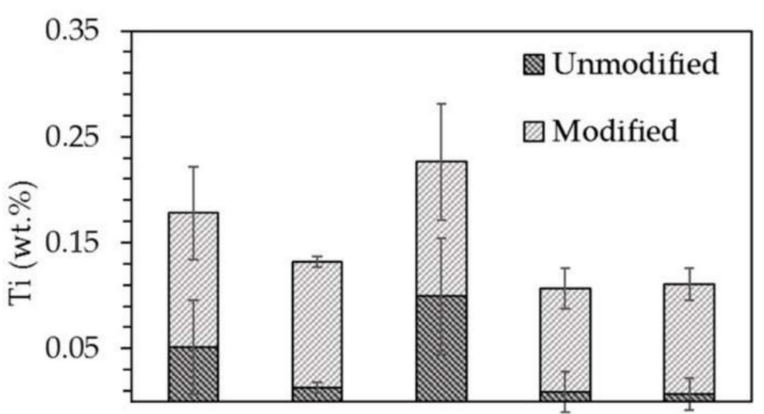

Alloy 1 Alloy 2 Alloy 3 Alloy 4 Alloy 5

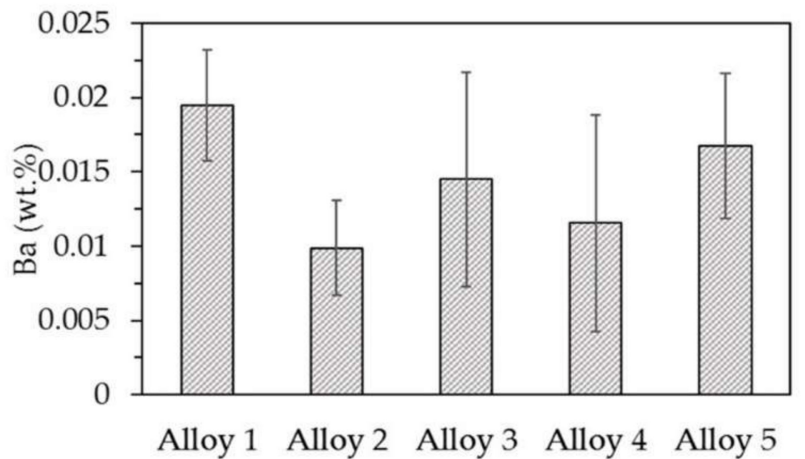

(b)

Figure 9. Mass concentration of modifying elements in Al-Si alloys according to spectral analysis data: (a) Ti, (b) Ba.

The long-term retention of the modification effect is critical for the casting of aluminium alloys. The comparative study of the effect of melt holding up to $5 \mathrm{~h}$ on the structure and mechanical properties of Al-12 $\mathrm{wt} \%$ Si binary alloy (alloy 4 ) treated with a complex flux was carried out.

The melt was held at a temperature of $720-740{ }^{\circ} \mathrm{C}$. The results were compared with the time of action of the sodium salt flux (standard flux).

The results of mechanical tests are given in Figure 10. According to the data obtained, the time of action of the complex flux during casting is $5 \mathrm{~h}$, while the standard flux retains its modifying effect only for $30 \mathrm{~min}$.

The structure of the alloy held up to $2 \mathrm{~h}$ is completely modified and represents a eutectic with the refined and spheroidized silicon (Figure 11). The average area of eutectic silicon increases from $0.48 \mu^{2}$ for no exposure to $2.1 \mu \mathrm{m}^{2}$ for $5 \mathrm{~h}$ exposure. Nevertheless, after $5 \mathrm{~h}$ of exposure, silicon is significantly refined compared to an unmodified alloy. The extension of the holding time up to $5 \mathrm{~h}$ results in the growth of the particles of eutectic silicon, which is caused by the partial burn-off of the modifying elements (Figure 11). 


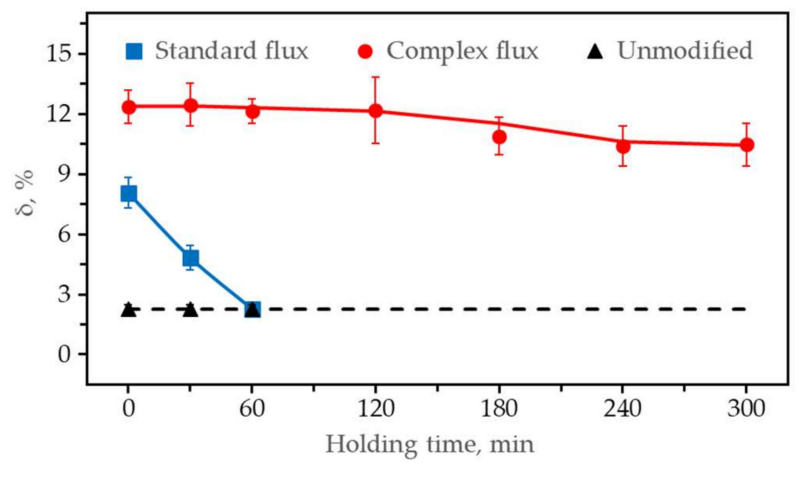

(a)

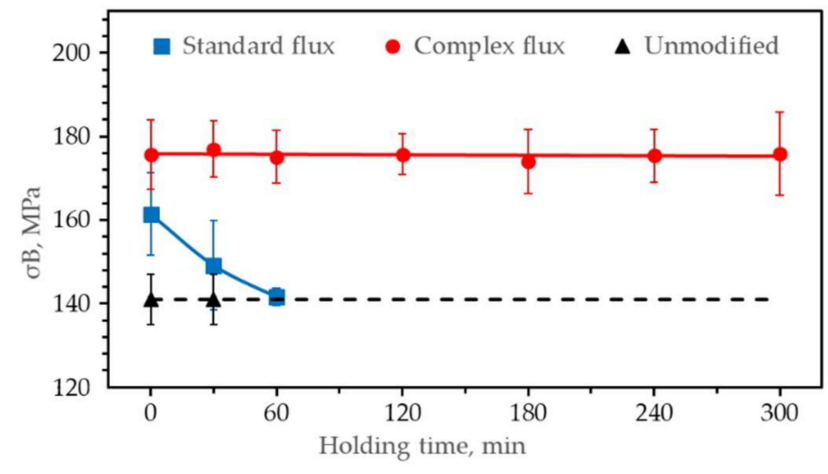

(b)

Figure 10. Influence of the holding time of the melt of the binary eutectic alloy Al-12\% wt. Si (alloy 4 ) on the relative elongation (a), ultimate strength $(\mathbf{b})$.
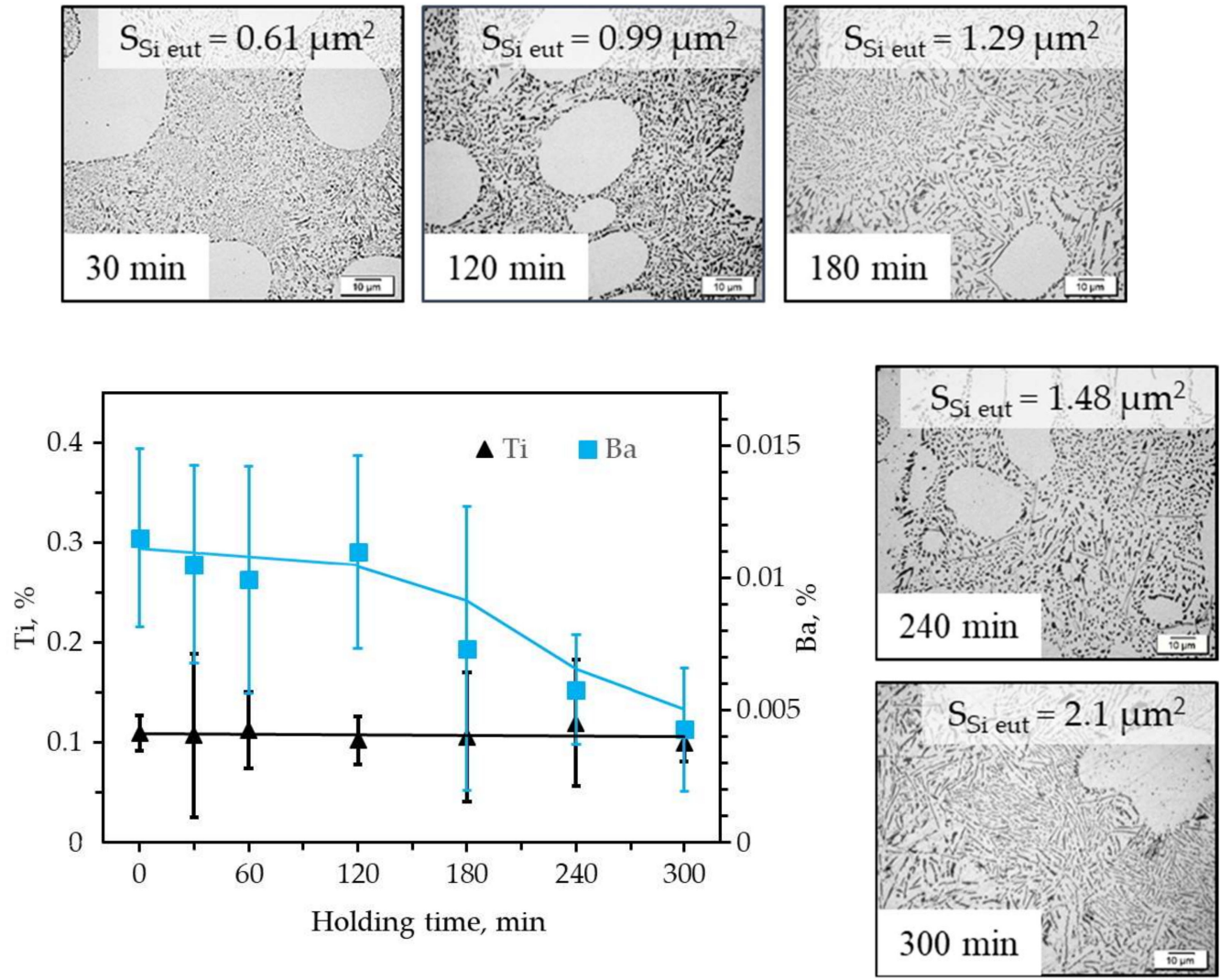

Figure 11. Microstructure and concentration (wt.\%) of modifying elements in Al-12\% wtSi alloy treated with a complex flux.

If the titanium concentration exceeds $0.2 \mathrm{wt} \%$, rough needles of the $\mathrm{TiAl}_{3}$ intermetallic phase are formed in the alloy, and the mechanical properties decrease [25]. The value of less than $0.05 \mathrm{wt} . \% \mathrm{Ti}$ is insufficient to modify the grain and $\alpha-\mathrm{Al}$ dendrites. The increased barium content may also worsen characteristics due to the formation and growth of the intermetallic phase based on barium, for example, $\mathrm{Al}_{2} \mathrm{Si}_{2} \mathrm{Ba}$ [17], and an insufficient amount may lead to incomplete modification of eutectic silicon.

\section{Conclusions}

The developed complex flux consists of available substances that are widely produced by the industry and has a significant effect on the mechanical properties and structure of hypoeutectic, eutectic, hypereutectic aluminium-silicon alloys. 
1. Compared to the modifier that is widely used in the industry, modification with a complex flux increases the strength of hypoeutectic and eutectic silumins by $10-32 \%$ and plasticity by $24-54 \%$ (depending on the alloy). Moreover, the developed flux reduces the size of primary silicon, which results in the increase in the properties of the hypereutectic alloy Al-17 wt $\%$ Si-Cu-Mg-Ni.

2. The improvement in the mechanical properties of alloys results from the complex effect of the flux components on the structure. The microstructural analysis established that all the main structural components of silumins, i.e., $\alpha$-Al dendrites, aluminium-silicon eutectic and primary silicon, are refined in the alloys modified with the complex flux. The SDAS and average area of eutectic silicon decreases in all the alloys as a consequence of addition of complex flux.

3. Another advantage of the complex flux compared to the standard sodium-containing flux is the long-term retention of the modifying effect.

4. The study results showed that the use of the complex modifier based on titanium dioxide is a promising direction for the improvement of the structure of aluminium casting alloys and increasing their mechanical properties.

5. Further studies are planned in relation to the combined effect of modifying elements of various types $(\mathrm{Ti}, \mathrm{Ba}, \mathrm{K})$ on the crystallization parameters and the size, shape and composition of the structural components of Al-Si casting alloys.

Author Contributions: Supervision, A.P.R.; writing-original draft preparation, A.D.S. and I.A.P.; writing-review and editing, A.D.S., I.A.P. and V.V.T.; investigations, A.D.S., I.A.P., E.V.M. and A.P.R. All authors have read and agreed to the published version of the manuscript.

Funding: The research was carried out within the state assignment (No. FUER-2019-0004).

Institutional Review Board Statement: Not applicable.

Informed Consent Statement: Not applicable.

Data Availability Statement: Not applicable.

Conflicts of Interest: The authors declare no conflict of interest.

\section{References}

1. Davis, J.R. (Ed.) Aluminium and Aluminium Alloys; ASM International: Materials Park, OH, USA, 1993 ; p. 627.

2. Hegde, S.; Prabhu, K.N. Modification of eutectic silicon in Al-Si alloys. J. Mater. Sci. 2008, 43, 3009-3027. [CrossRef]

3. Mazahery, A.; Shabani, M.O. Modification mechanism and microstructural characteristics of eutectic Si in casting Al-Si alloys: A review on experimental and numerical studies. JOM 2014, 66, 726-738. [CrossRef]

4. Moniri, S.; Shahani, A.J. Chemical modification of degenerate eutectics: A review of recent advances and current issues. J. Mater. Res. 2019, 34, 20-34. [CrossRef]

5. Gursoy, O.; Timelli, G. Lanthanides: A focused review of eutectic modification in hypoeutectic Al-Si alloys. J. Mater. Res. Technol. 2020, 9, 8652-8666. [CrossRef]

6. Lu, L.; Nogita, K.; Dahle, A.K. Combining Sr and Na additions in hypoeutectic Al-Si foundry alloys. Mater. Sci. Eng. A 2005, 399, 244-253. [CrossRef]

7. Wang, J.; Liu, Y.; Zhu, J.; Liu, Y.; Su, X. Effect of Complex Modification on Microstructure and Mechanical Properties of Hypoeutectic Al-Si. Metallogr. Microstruct. Anal. 2019, 8, 833-839. [CrossRef]

8. Nikitin, K.V. Modification and Complex Treatment of Silumins: A Textbook, 2nd ed.; Samara State Technical University: Samara, Russia, 2016; 92p.

9. Shlyaptseva, A.D.; Petrov, I.A.; Ryakhovskii, A.P. Prospects of using titanium dioxide as a component of modifying composition for aluminium casting alloys. Mater. Sci. Forum 2019, 946, 636-643. [CrossRef]

10. Volochko, A.T. Modification of eutectic and primary silicon particles in silumins. Development Prospects. Cast. Metall. 2015, 4, 38-44.

11. Wu, D.Y.; Kang, J.; Feng, Z.H.; Su, R.; Liu, C.H.; Li, T.; Wang, L.S. Utilizing a novel modifier to realize multi-refinement and optimized heat treatment of A356 alloy. J. Alloys Compd. 2019, 791, 628-640. [CrossRef]

12. Zhao, H.L.; Bai, H.L.; Wang, J.; Guan, S.K. Preparation of Al-Ti-C-Sr master alloys and their refining efficiency on A356 alloy. Mater. Character. 2009, 60, 377-383. [CrossRef]

13. Qiu, C.; Miao, S.; Li, X.; Xia, X.; Ding, J.; Wang, Y.; Zhao, W. Synergistic effect of Sr and La on the microstructure and mechanical properties of A356.2 alloy. Mater. Des. 2017, 114, 563-571. [CrossRef] 
14. Shlyaptseva, A.D.; Petrov, I.A.; Ryakhovsky, A.P.; Moiseev, V.S.; Bobryshev, B.L.; Azizov, T.N. Method for Modifying AluminumSilicon Alloys. Patent RU 2,743,945,C1, 1 March 2021.

15. Knuutinen, A.; Nogita, K.; McDonald, S.D.; Dahle, A.K. Modification of Al-Si alloys with Ba, Ca, Y and Yb. J. Light Met. 2001, 1, 229-240. [CrossRef]

16. Sha, X.; Chen, X.; Ning, H.; Xiao, L.; Yin, D.; Mao, L.; Zheng, J.; Zhou, H. Modification of Eutectic Si in Al-Si-(Ba) Alloy by Inducing a Novel 9R Structure in Twins. Materials 2018, 11, 1151. [CrossRef]

17. Rao, J.; Zhang, J.; Liu, R.; Zheng, J.; Yin, D. Modification of eutectic Si and the microstructure in an Al-7Si alloy with barium addition. Mater. Sci. Eng. A 2018, 728, 72-79. [CrossRef]

18. Zhang, X.H.; Su, G.C.; Ju, C.W.; Wang, W.C.; Yan, W.L. Effect of modification treatment on the microstructure and mechanical properties of Al-0.35\%Mg-7.0\%Si cast alloy. Mater. Des. 2010, 31, 4408-4413. [CrossRef]

19. Nogita, K.; Knuutinen, A.; McDonald, S.D.; Dahle, A.K. Mechanisms of eutectic solidification in Al-Si alloys modified with Ba, $\mathrm{Ca}, \mathrm{Y}$ and $\mathrm{Yb}$. J. Light Met. 2001, 1, 219-228. [CrossRef]

20. Samuel, E.; Golbahar, B.; Samuel, A.M.; Doty, H.W.; Valtierra, S.; Samuel, F.H. Effect of grain refiner on the tensile and impact properties of Al-Si-Mg cast alloys. Mater. Des. 2014, 56, 468-479. [CrossRef]

21. Lipinski, T. Influence of Ti and Melt Number on Microstructure and Mechanical Properties of Al-Si Alloy on Agriculture Machine Parts; Engineering for Rural Development: Jelgava, Latvia, 2018; pp. 1431-1436. [CrossRef]

22. Wang, S.; Liu, Y.; Peng, H.; Lu, X.; Wang, J.; Su, X. Microstructure and mechanical properties of Al-12.6Si eutectic alloy modified with Al-5Ti master alloy. Adv. Eng. Mater. 2017, 19, 1700495. [CrossRef]

23. Wu, Y.; Zhang, J.; Liao, H.; Li, G.; Wu, Y. Development of high performance near eutectic Al-Si-Mg alloy profile by micro alloying with Ti. J. Alloys Compd. 2016, 660, 141-147. [CrossRef]

24. Li, P.; Liu, S.; Zhang, L.; Liu, X. Grain refinement of A356 alloy by Al-Ti-B-C master alloy and its effect on mechanical properties. Mater. Des. 2013, 47, 522-528. [CrossRef]

25. Napalkov, V.I.; Makhov, S.V.; Popov, D.A. Production of additions for aluminum alloys. Met. Sci. Heat Treat. 2012, 53, 478-483. [CrossRef]

26. Makhov, S.V.; Kozlovskiy, G.A.; Moskvitin, V.I. The concepts of the process of aluminothermic obtaining of Al-Ti Master alloy from TiO2 dissolved in chloride-fluoride melt. Tsvetnye Met. 2015, 11, 34-38. [CrossRef]

27. Maeda, M.; Yahata, T.; Mitugi, K.; Ikeda, T. Aluminothermic Reduction of Titanium Oxide Materials Transactions. JIM 1993, 34, 599-603.

28. Shlyaptseva, A.D.; Petrov, I.A.; Ryakhovsky, A.P.; Moiseev, V.S. Investigation of aluminothermic reduction of titanium dioxide in the aluminium melt. Found. Russ. 2019, 11, 8-19.

29. Hatem, G. Calculation of phase diagrams for the binary systems BaF2-KF and KF-ZrF4 and the ternary system BaF2-KF-ZrF4. Thermochim. Acta 1995, 260, 17-28. [CrossRef]

30. Frolov, K.V. Blank production technology. In Mechanical Engineering; Masinostroenie: Moscow, Russia, 2004; Available online: https: / / bookree.org/reader?file=476656\& (accessed on 15 October 2021).

31. William, F.; Gale Terry, C. (Eds.) Smithells Metals Reference Book, 8th ed.Totemeier Imprint: Oxford, UK, 2003 ; p. 2080.

32. Belov, N.A. Phase Composition of Industrial and Promising Aluminium Alloys: Monograph; MISiS Publishing House: Moscow, Russia, 2010; 511p.

33. Vandersluis, E.; Ravindran, C. Comparison of Measurement Methods for Secondary Dendrite Arm Spacing. Metallogr. Microstruct. Anal. 2017, 6, 89-94. [CrossRef]

34. Fracchia, E.; Gobber, F.S.; Rosso, M. Effect of Alloying Elements on the Sr Modification of Al-Si Cast Alloys. Metals 2021, 11, 342. [CrossRef] 